\title{
The Association between Family Structure Changes and High School Completion in South Africa
}

\author{
Annah Vimbai Bengesai ${ }^{1, *(1)}$ and Nompumelelo Nzimande ${ }^{2}$ \\ 1 Teaching and Learning Unit, University of KwaZulu-Natal, Durban 4000, South Africa \\ 2 School of Built Environment and Development Studies, University of KwaZulu-Natal, Durban 4000, \\ South Africa; Nzimanden@ukzn.ac.za \\ * Correspondence: bengesai@ukzn.ac.za
}

Received: 2 June 2020; Accepted: 30 June 2020; Published: 29 July 2020

\begin{abstract}
Over the past few years, family structures have been dramatically transformed, yet limited research from South Africa has assessed the effect on children's developmental outcomes. Using data from the National Income Dynamics Study, we aim to contribute to the literature by examining the relationship between family structure disruption and high school completion in South Africa. Our sample consisted of 1649 young people who were aged 12, 13 and 14 in 2008 and their educational attainment was tracked through to 2017. The results from the logistic regression analysis demonstrate that family structure disruption is negatively associated with high school completion. After controlling for variation in household income change, the child's educational factors and socio-demographic controls, young people who experienced a change from a co-resident family or were in stable non-resident parent family structures were up to $50 \%$ less likely to complete high school relative to those from undisrupted co-resident parent family structures. Given that family structure disruption is a widespread phenomenon in South Africa, research should consider it as a key determinant of educational attainment and policymakers should come up with holistic interventions to support families as well as allocate public resources in ways that can help reduce educational inequalities.
\end{abstract}

Keywords: educational attainment; high school completion; family structure disruption; South Africa

\section{Introduction}

Although South Africa has invested in access to education since the demise of apartheid, research suggests that the majority of young people still do not complete high school, with some scholars calling the high dropout rates a crisis (Weybright et al. 2017). It is estimated that $50 \%$ of learners who enter Grade 1 at a particular time leave without completing high school (Spaull 2015). This status quo suggests that there are still significant barriers in educational attainment prompting the following questions: What are some of the factors that influence high school completion and why are some learners more successful than others? Existing research has attempted to answer these questions, focusing mainly on the association between educational attainment and school quality, demographic factors, family background, in particular, parental education, as well as sexual behaviour (Bengesai et al. 2018; Weybright et al. 2017; Spaull 2015; Branson et al. 2014; Marteleto et al. 2008). However, the effect of other family dynamics, such as family structure, and in particular, family structure disruption is less explored.

In recent years, and especially so in South Africa, family structures have been dramatically transformed, a situation that has been partly attributed to the decline in marriage rates, the rise in non-marital fertility as well as divorce rates (Posel and Rudwick 2013; Chuong and Operario 2012). South Africa also has a legacy of family disruption, which was orchestrated by the apartheid system through past laws, urban housing policy and the creation of the homelands (Budlender and Lund 2011). 
Accordingly, the country has one of the lowest rates of co-resident parents in the world (Hall and Sambu 2018). For instance, the General Household Survey of 2016 revealed that only $25 \%$ of South African households were 'traditional' families consisting of married parents and their children (Statistics South Africa Stats SA (2017)). These family dynamics have been further compounded by the HIV epidemic, which has left many children orphaned (Chuong and Operario 2012; Monash and Boerma 2004). Consequently, many children today reside in diversified family contexts, which has implications for their developmental outcomes, including educational attainment.

Globally, some studies have recognised family structure as a risk factor for children's educational outcomes. Although mainly dominated by the West, (Cid and Stokes 2013, Uruguay; Monserud and Elder 2011; Martin 2012, USA; Frisco et al. 2007, USA), this body of literature has consistently shown that children in 'intact' families have better outcomes across different educational indicators. When examining the effect of family structure on school dropout and falling behind, Cid and Stokes (2013) found that children raised in non-traditional families (without both biological parents) had negative outcomes, with more adverse effects for girls. Others have also shown that growing up in single-parent families might reduce the chances of completing high school and enrolling in post-secondary education (Monserud and Elder 2011; Astone and McLanahan 1991). Similarly, the few studies from sub-Saharan Africa seem to concur with these findings. Using Demographic and Health Survey data from 26 countries, Amoateng et al. (2017) found that children born into monogamous families completed more years of schooling than those in polygamous or single-parent families. Abuya et al. (2019) found that Ghanaian children in two-parent households were most likely to be in the right age for the grade they were enrolled in relative to those from single-parent families or those who lived with guardians. In South Africa, Ndagurwa and Nzimande (2016) study examined the effect of family structure on school enrolment and dropout, focusing on children aged 7-17 years, while Anderson (2003) explored the association between family structure and school enrolment as well as the highest grade completed per year. Both of these studies found that children in co-resident parent families had the most favourable outcomes.

Several theoretical frameworks have been used to explain how family structure affects educational attainment. Drawing on the sociological work of Coleman (1988) and Bourdieu (1986), some scholars have theorised the relationship between familial resources and educational attainment in terms of capital, suggesting that a child's wellbeing and success in life is contingent upon the different forms of capital that are transmitted by their parents since they are dependent on them for resources (Humble and Dixon 2017; Martin 2012). Within this framework, family background is considered a strong form of capital that has three interrelated components; human capital, financial capital, and social capital. As Martin (2012, p. 34) notes, "families must have strong social capital to transmit the necessary financial and human capital for their child's human capital development".

Becker's household theory, which posits that children's educational attainment is a valued commodity in the family, has also been influential in the research on the family structure (Abuya et al. 2019). To produce this commodity, parents invest inputs such as time and money (Monserud and Elder 2011), and by extension, the quality of the output depends on the quality of the inputs. For example, lone parenthood is often likened to low socioeconomic status, social isolation, and lower parental support for children (Amoateng et al. 2017; Martin 2012; Uwaifo 2012). This is mainly because females, who historically are less educated and likely to be employed in less prestigious occupations (Schatz et al. 2011), head most single-parent families, especially in South Africa. Thus, it is assumed that children from single-headed or non-resident parent families are likely to suffer from economic vulnerability as well as structural deficiency related to lack of parental involvement in their welfare (Monserud and Elder 2011; Martin 2012). On the contrary, co-resident parents are seen as more attractive in transmitting socioeconomic resources to their children (Cid and Stokes 2013).

While previous studies on family structure contain numerous insights, there are significant gaps that need to be addressed. For instance, the family is an institution that is continuously evolving. This is much more pronounced in South Africa where the family structure is consistently showing 
changing characteristics, with double orphaned children, female-headed families and non-marital fertility being a persistent issue (Sooryamoorthy and Makhoba 2016; Chuong and Operario 2012; Madhavan and Schatz 2007). Given the decreasing likelihood that children will stay in 'intact' families across their life course, it is critical to understand how these transitions may affect their outcomes. Moreover, most of the research on family structure has relied on snapshots or 'window observations' (Sun and Li 2011; Lee and McLanahan 2015) of family situations taken at one point in a young person's life. These observations are then extrapolated to the entire childhood, which is likely to be misleading and insensitive to the demographic shifts in family structure. The aim of this paper is, therefore, to move beyond this static examination of family structure, to an approach that recognises family structure transitions.

\section{Family Structure Transitions and Children's Educational Outcomes}

Although scholars such as Furstenberg and Seltzer (1986) started speculating about the effect of family structure change (also called instability) on children's outcomes as early as the 1980s, much less attention has been paid to this aspect (Fomby and Cherlin 2007) especially in the empirical studies from Sub-Saharan Africa, including South Africa. Thus, the influence of family structure transitions is a much less theorised topic in South Africa, and most of what is known emanates from contexts where socio-cultural norms may differ. This limitation notwithstanding, there is strong evidence internationally which has shown that changes in family structure can potentially produce stresses for children that are distinct from the family structure (Goldberg 2013; Steele et al. 2009; Fomby and Cherlin 2007). This body of evidence, which is informed by the family stress theory, argues that the disparities in child educational outcomes arise from the stress caused by the family structure disruptions (Sun and Li 2011; Fomby and Cherlin 2007). This is because family structure disruption is likely to cause a reduction in resources (financial and time) due to the absence of a parent in the same household or other harmful changes such as fluctuating changes in parental roles and family routines (Hampden-Thompson and Galindo 2015; Steele et al. 2009).

Taking this hypothesis to be true suggests that family structure stability (i.e., absence of changes) might just be as protective against negative outcomes (Sun and Li 2011). Put differently, a child born to a single parent might be better off if the parent does not cohabit or marry. This is because children who do not experience any family structure disruptions are likely to be protected from the emotional stress associated with dramatic changes in parenting practices (Fomby and Cherlin 2007). Thus, consistency over time might also be as important for young people's developmental outcomes. However, most of the studies on family structure instability have not considered this different perspective, choosing instead to focus on measuring the number of family structure changes and the marital status of the resident parents (Hampden-Thompson and Galindo 2015; Fomby and Cherlin 2007) as more significant than the "type of family change (e.g., exit versus entrance of a parent" (Lee and McLanahan 2015). In a country with the lowest rates of co-resident parents and declining nuptiality, capturing the residency of parents might be crucial in measuring the interaction between family structure and children's outcomes.

A further limitation in the literature on family instability relates to whether all family structure changes are equally harmful to children (Lee and McLanahan 2015). This aspect has not been sufficiently addressed in prior studies as the tendency has been to compare children from alternative family structures with those from co-resident biological parent families. While comparing co-resident families and those experiencing transitions gives us insights into the effect of family structure disruption, it might obscure some of the dynamics and mechanisms through which instability affects educational outcomes. As Lee and McLanahan (2015) put it, a child cannot move out of a two-parent family if they resided with a single parent or had no residential parent. Likewise, a child cannot move into a two-parent family if he or she already lived with both parents, except in cases of step-parent co-residence (Lee and McLanahan 2015).

Our study, therefore, will extend the existing literature in several ways. First, we examine whether family structure changes are associated with high school completion. In particular, we focus on the 
following family structure disruption statuses: between non-disrupted single-parent, two-parent and non-resident parent families and the disrupted counterparts. Thus, we focus on parents' residential status rather than their marital status. To our knowledge, this is the first study in South Africa that has examined this aspect and will, therefore, extend the existing international literature (for instance, (Sun and Li 2011; Lee and McLanahan 2015)) by providing an African perspective. Second, we will compare the effect of changes (moving in and moving out of parents) on subgroups that were similar at the beginning of the observation period (e.g., the moving out of a parent from a lone parent family structure vis a viz a stable lone parent family). We hypothesise that not all transitions are the same. For instance, moving from a lone parent structure to a co-residential union might increase access to parental resources such as time and money. (Lee and McLanahan 2015). Yet, it might also interrupt family routines, leading to stressful parent-child relationships (Fomby and Cherlin 2007). Similarly, while moving out of a co-residential union is expected to be harmful to children as it potentially reduces the family's resources; however, such a move might be beneficial to young people in situations where there is conflict in the parental relationship.

\section{Methods}

\subsection{The Data}

Data for this study was drawn from the five waves of the National Income Dynamic Study (NIDS) a longitudinal panel survey of the dynamic structure of households and changes in living conditions in South Africa (Murray et al. 2010). Individuals who were aged 12, 13 and 14 at wave 1 (2008) were singled out. We acknowledge that our sample falls short in capturing changes that might have occurred in early childhood (i.e., below the age of 11), which have been shown to have a significant influence on children's outcomes. Nonetheless, our sample is still superior to snapshot measures of family structure that have been used in the majority of the earlier South African studies.

Given that high school completion cannot be achieved before the age of at least 18 or 19 in South Africa, we gave a few more years for the sample to complete the high school cycle, considering that some might have started school late or repeated a grade. Thus, the youngest in our sample were at least aged 21 and the oldest 23 by wave 5 (in 2017). The NIDS used a stratified two-stage cluster sampling, which involved first selecting 400 Primary Sampling Units from 53 District Councils in the country. From these, 8 non-overlapping clusters of dwelling units were systematically selected.

Analysing family structure changes requires detailed longitudinal data, and the NIDS dataset is well suited for this as it contains information about the family's living arrangements, household characteristics as well as children's educational characteristics, which are the key explanatory variables in this study. However, while the panel nature of this data controls for unobserved characteristics that might influence the association between family structure and educational outcomes, it also raises other challenges such as attrition between waves which is likely to impact on the validity of the study (Baigrie and Eyal 2013). For instance, attrition between wave 1 and wave 2, wave 2 and wave 3 as well as wave 3 and wave 4 was 21.95\%,15.82\%, and 13.75\%, respectively (Chinhema et al. 2016). Assuming this attrition occurred non-randomly, selection bias would have been introduced as the remaining sample would not have been representative of the target population. To address these problems, we used panel weights provided in the NIDS dataset to adjust for attrition between waves.

\subsection{Dependent Variable}

The outcome of interest in this study was high school completion ( $0=$ No, $1=$ Yes) by the ages 21-23 or earlier. This outcome was structured using the information available pertaining to the highest level of education attained by wave 5 in 2017. 


\subsection{Independent Variables}

Family structure transition was measured as the type of family structure change a child experienced since the ages 12-14 years. We chose these particular age groups, given that our focus was on high school completion. Much younger age groups surveyed in 2008 would not have completed high school by 2017.

In the NIDS data, respondents were asked questions pertaining to the residential status of the parents. If there was any change in the number or identity (resident father or mother) of the parents in the household from one wave to another, the child was considered to have experienced a family structure change. Using this information, we classified children as residing in two biological parents, single parent and no parent family structures at wave 1 . We had initially sought to classify single-parent families as single mother and single father families; however, due to the small sample sizes for the father only category, we decided to collapse these into single-parent families. To increase the sample size, we also used information on whether the mother or father was alive at each wave. The breakdown of these family structures at each wave is presented in Table 1.

Table 1. Breakdown of family structure by wave (National Income Dynamic Study (NIDS) wave 1-4).

\begin{tabular}{ccccc}
\hline Family Structure Type & Wave $\mathbf{1}$ & Wave $\mathbf{2}$ & Wave 3 & Wave 4 \\
\hline Co-resident parents & 537 & 345 & 353 & 275 \\
Non-resident parents & 380 & 135 & 199 & 251 \\
Lone parent & 477 & 646 & 785 & 819 \\
Total & 1394 & 1126 & 1337 & 1345 \\
\hline
\end{tabular}

Using these composite variables at Wave 1 (both parents, lone-parent and non-resident parent), and tracking the children through to Wave 4, we then identified the following types of family structure transitions: (a) stable co-resident parent families (b) stable lone-parent families and (c) stable non-resident parent families. We did not include wave 5 for the family structure change variable given this change would have happened in early adulthood. For families that experienced changes between Wave 1 and Wave 4, we identified the following structures: (d) disrupted co-resident parent families (e) disrupted lone-parent and (f) disrupted non-resident parent families. Acknowledging that family structure transitions differ, and the moving in of a parent family might have a different effect on children than the moving out, we also conducted a subgroup analysis of individuals who experienced the: (i) exit of a parent(s) from a co-resident parent family vs. those who remained in stable co-resident parent families; (ii) exit of a parent from a lone-parent family vs. stable lone-parent families; (iii) entrance of one or both parents vs. stable non-resident family structure and (iv) entrance of a parent to a lone parent or non-resident family structure. The breakdown and percentages of the family structure changes that the young people in our sample experienced is shown in Table 2 below.

Table 2. Breakdown of family structure by disruption status (NIDS wave 1-4).

\begin{tabular}{lcc}
\hline \multicolumn{1}{c}{ Parental Residential Status } & Unweighted Freq. & $\%$ \\
\hline Families that did not experience disruption & & \\
Undisrupted co-resident & 242 & 14.7 \\
Undisrupted non resident & 398 & 24.1 \\
Undisrupted lone parent & 347 & 21.0 \\
\hline Families that experienced disruption & & \\
Disrupted co-resident & 207 & 12.6 \\
Disrupted non resident & 164 & 10.0 \\
Disrupted lone parent & 291 & 17.7 \\
\hline
\end{tabular}


Table 2. Cont.

\begin{tabular}{lcc}
\hline \multicolumn{1}{c}{ Parental Residential Status } & Unweighted Freq. & \% \\
\hline Subgroup & & \\
Exit of a parent(s) from a co-resident family & 171 & 10.4 \\
Exit of a parent from a lone parent family & 194 & 11.8 \\
Entrance of a parent(s) into a lone or non-resident family & 135 & 8.2 \\
Entrance of a parent into a non-resident parent family & 110 & 6.7 \\
Multiple transitions & 27 & 1.6 \\
\hline
\end{tabular}

Table 2 presents the young people's family structure changes across four waves (wave 1-4 only). The results show that $24.1 \%$, did not reside with either of their parents, while approximately $21 \%$ lived with a lone parent, most of whom were the mothers. Only $14.7 \%$ of the young people lived in undisrupted two-parent households. We also find that approximately $38 \%$ of the young people had experienced family structure disruption, $12.6 \%$ had experienced the exit of a parent from a two-parent family structure, $10.0 \%$ of those who did not reside with any parent at wave 1 had a parent move in, while $17.7 \%$ of children in lone-parent families experienced the exit of a parent.

In the subgroup analysis, we notice that $10.4 \%$ of young people who resided with both parents had experienced the exit of a parent, while $11.8 \%$ of those in lone-parent family structures experienced the moving out of a parent. Out of those who resided in lone-parent or non-resident parent family structures $8.2 \%$ had a parent move in, $6.7 \%$ of those who were in non-resident parent family structures also had a parent moving in. Less than $2 \%$ of young people in our sample experienced multiple transitions, which involved for instance, the exit of mother and entrance of a father of vice-versa, the exit of both parents in one wave and the entrance in another. This group was not included in the statistical analysis given the small sample size

\subsubsection{Family Resources}

Family income has been identified as one of the key indicators of social capital and familial resources associated with children's better life outcomes (Assari 2018). Therefore, to gauge the association between resources and family structure disruption, we calculated the changes in household income between Waves 1 and Wave 4. A positive change in household income between the two waves was coded as (1) while a negative change was coded (0). Prior studies have also included variables such as mother's and father's education as measures of family resources (Tsiplakides 2018; Li et al. 2019). However, due to a large number of missing values on both mother and father's education, we opted to combine both mother and father's education into a composite variable, parental education. For instance, if the mothers' highest grade was primary (value $=0$ ) and father's was complete secondary (value $=2$ ), parental education was computed as 2 . We acknowledge that this categorisation has the potential to mask significant heterogeneity as it does not differentiate between mothers and fathers' education. However, given the data limitations, we worked on the plausible assumption that at least one parent in that family had that highest level of education. This modified parental education increased the sample size to 1234. Again, considering that most of the missing values for both mother and father's education were on children in stable co-resident families, we decided to include missing values as a dummy variable. Thus, our parental education variable had the following categories: $(1=$ primary or less; 2 = some secondary education; $3=$ high school; and, $4=$ missing).

\subsubsection{Child's Academic Characteristics}

One potential driver of educational attainment which is also a significant feature of the South African education system is grade repetition (Branson et al. 2014). As such, we also included a dummy variable that indicated whether a child had repeated a grade or not (0/1). 


\subsection{Control Variables}

Demographic factors such as age, population group/race and place of residence were used as controls. Owing to the low sample sizes for the following racial categories (Blacks, Indians and Whites) we opted for a two-category population group variable to represent ( 0 = 'Other', $1=$ Black South African). Research has consistently shown that Black South African students have worse educational outcomes relative to their peers from the other population groups. Therefore, we reasoned that this categorisation would at least give us information about this particular risk group. We use race in this study as a social construct rooted in South African history of apartheid, and which continues to impact on educational attainment.

\subsection{Analytic Strategy}

Given that our outcome variable, high school completion was binary, we used logistic regression models. We estimated three models for the type of family structure transition. In Model 1 we estimated the effect of any changes in family structure and household income. Model 2 included family structure changes, household income changes, repeating a grade and all the demographic controls, while Model 3 controlled for parental education in addition to all variables included in Model 2. We similarly constructed separate models for the subgroups, to capture the effect of moving in and moving out of parents across the three family structures identified at Wave 1. As recommended by Wittenberg (2009), post stratified weights were applied to make the sample representative of the South African population while adjusting for under or oversampling. We also used the svy commands in Stata v.14 to adjust for the stratified sampling.

\section{Results}

\subsection{High School Completion by Family Structure Transitions and Changes in Household Income}

Figure 1 shows the distribution of the sample by educational attainment. We find that approximately $46 \%$ of the young people had at least 12 years of schooling, followed by about $20 \%$ with at least 11 years of schooling. Only a few young people (about 3\%) had at least post-secondary education (more than 13 years).

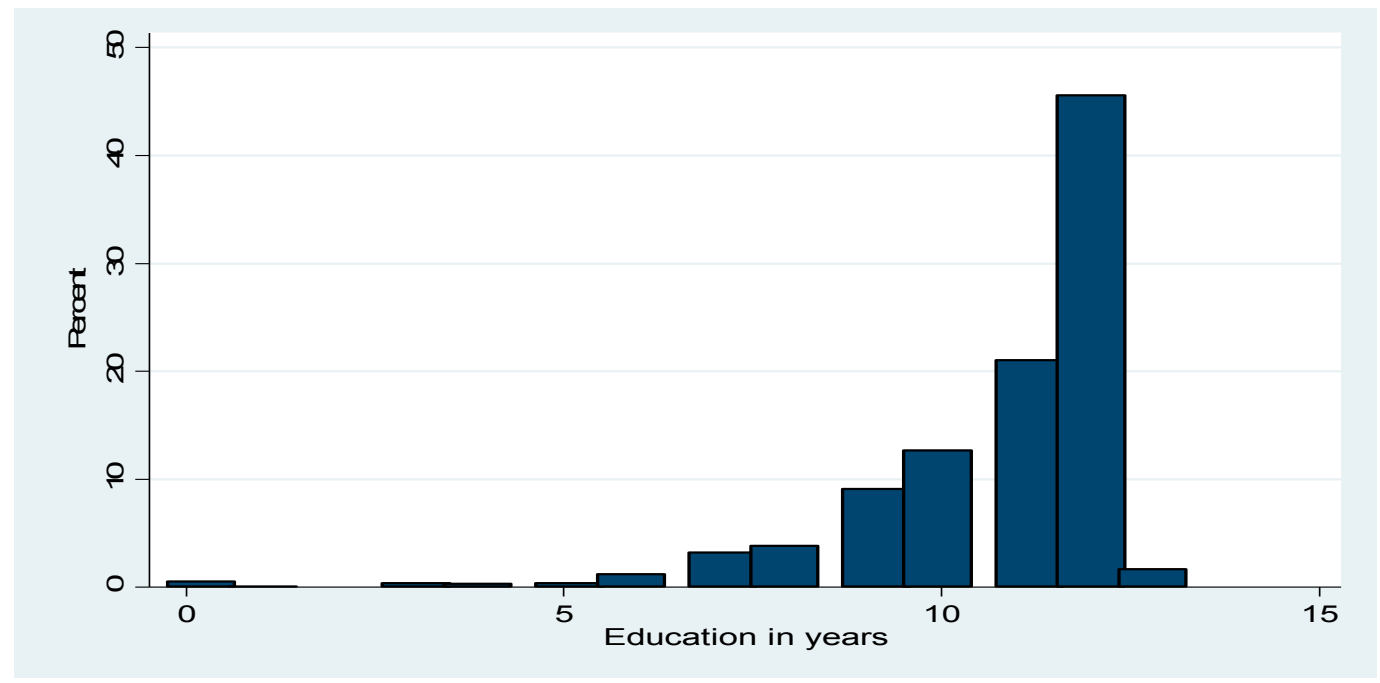

Figure 1. Distribution of the outcome variable (NIDS wave 5).

Table 3 presents the descriptive statistics of the distribution of high school completion by family structure and disruption statuses and household income changes. Approximately 50\% of the young people had completed high school by the ages 21-23, while young people from undisrupted two-parent family structures and disrupted lone-parent families had the most favourable outcomes. These results 
also show that young people from undisrupted lone-parent and disrupted co-resident parent families were the least likely to complete high school, while those from non-resident and disrupted non-resident parent families were more similar in terms of high school completion. This analysis, therefore, provides some initial evidence that family structure disruption could account for high school completion in South Africa. We also find that most of our variables, except for race and household income change, were significantly associated with high school completion.

Table 3. Descriptive statistics for high school and association with family structure change and other variables (NIDS, waves 1-5).

\begin{tabular}{|c|c|c|c|}
\hline Variables & $\begin{array}{l}\text { Unweighted } \\
\text { Freq. }\end{array}$ & $\begin{array}{l}\text { High School } \\
\text { Completion }\end{array}$ & Sig. \\
\hline Total & 1649 & 49.7 & \\
\hline Family Structure Transitions & & & $* *$ \\
\hline Undisrupted co-resident parents & 242 & 55.0 & \\
\hline Undisrupted non-resident parents & 398 & 46.0 & \\
\hline Undisrupted lone parent & 347 & 41.5 & \\
\hline Disrupted co-resident & 207 & 43.0 & \\
\hline Disrupted non-resident parents & 164 & 46.3 & \\
\hline Disrupted lone parent & 291 & 48.8 & \\
\hline \multicolumn{4}{|l|}{ Subgroup analysis } \\
\hline Exit of a parent(s) from a co-resident family & 171 & 42.1 & $* *$ \\
\hline Exit of a parent from a lone parent family & 194 & 50.0 & ** \\
\hline Entrance of a parent(s) into a lone or non-resident family & 135 & 43.6 & \\
\hline Entrance of a parent to a non-resident parent family & 110 & 45.2 & * \\
\hline \multicolumn{4}{|l|}{ Household Income change } \\
\hline Positive change & 352 & 47.7 & \\
\hline Negative change & 1261 & 47.1 & \\
\hline \multicolumn{4}{|l|}{ Controls } \\
\hline Gender & & & $* * *$ \\
\hline Male & 874 & 41.2 & \\
\hline Female & 839 & 51.0 & \\
\hline \multicolumn{4}{|l|}{ Race } \\
\hline African & 46.1 & 1472 & \\
\hline ‘Other' & 45.6 & 241 & \\
\hline Residence & & & * \\
\hline Urban & 620 & 49.0 & \\
\hline Non-urban & 1093 & 44.3 & \\
\hline Grade repetition & & & $* * *$ \\
\hline Yes & 764 & 30.8 & \\
\hline No & 917 & 59.9 & \\
\hline Parental Education & & & $* * *$ \\
\hline Primary or less & 491 & 33.0 & \\
\hline Some secondary & 425 & 43.5 & \\
\hline Complete secondary or more & 318 & 66.4 & \\
\hline Missing & 479 & 48.0 & \\
\hline
\end{tabular}

\subsection{Family Structure Instability and High School Completion}

Table 4 presents the logistic regression estimations for high school completion. In Model 1, we estimated the effect of two predictors: family structure changes and household income change. The results demonstrate that, except for young people from disrupted lone-parent families, there are significant differences in high school completion between undisrupted two-parent families and all other types of family structure transitions. Relative to young people in undisrupted co-resident family 
structures, those in disrupted or other undisrupted family structures were less likely to complete high school (OR = 0.49-0.58). Of note from Model 1 is the fact that young people from disrupted co-resident families had the least favourable outcomes $(\mathrm{OR}=0.49)$. We also find that those who had a negative change or no change in income had increased odds of completing high school, although this effect was not statistically significant. Model 2 included the key controls (gender, race, place of residence, and whether or not a child had repeated a grade). We find that the associations for all the other family structure types attenuated to non-significant except for the disrupted two-parent families who were $46 \%$ less likely to complete high school relative to those in undisrupted co-resident parent families. Among the controls, repeating a grade significantly reduced the probability of high school completion by a factor of 0.24 , while being female increased the odds by $44 \%$.

Table 4. Logistic regression models estimating the effect of family structure changes on high school completion (NIDS, waves 1-5).

\begin{tabular}{|c|c|c|c|c|c|c|}
\hline \multirow{2}{*}{ Variables } & \multicolumn{2}{|c|}{ Model 1} & \multicolumn{2}{|c|}{ Model 2} & \multicolumn{2}{|c|}{ Model 3} \\
\hline & OR & CI & aOR & CI & aOR & CI \\
\hline \multicolumn{7}{|l|}{$\begin{array}{l}\text { Family structure changes } \\
\text { (Ref-co-resident parent family) }\end{array}$} \\
\hline Non disrupted-non-resident parent & $0.58^{* *}$ & $0.34-0.97$ & 0.69 & $0.40-1.16$ & $0.49 * *$ & $0.23-1.02$ \\
\hline Non disrupted-lone-parent & $0.58 * *$ & $0.34-0.99$ & 0.71 & $0.42-1.21$ & 0.57 & $0.28-1.12$ \\
\hline Disrupted-co-resident parents & $0.49^{* * *}$ & $0.27-0.89$ & $0.54^{* *}$ & $0.31-1.03$ & $0.51 *$ & $0.24-1.06$ \\
\hline Disrupted-non-resident parent & $0.57^{* * *}$ & $0.31-1.04$ & 0.84 & $0.45-1.58$ & 0.65 & $0.29-1.45$ \\
\hline Disrupted lone parent & 0.88 & $0.51-1.52$ & 1.22 & $0.69-2.16$ & 0.93 & $0.44-1.93$ \\
\hline $\begin{array}{l}\text { Household Income Change (Ref is } \\
\text { positive change) }\end{array}$ & 1.05 & $0.74-1.51$ & 1.07 & $0.71-1.59$ & 0.96 & $0.63-1.46$ \\
\hline Gender (Ref- Male) & & & $1.44^{* *}$ & $1.04-2.00$ & $1.56^{* * *}$ & $1.12-2.19$ \\
\hline Race (Ref-Other) & & & 1.08 & $0.60-1.95$ & 1.09 & $0.62-1.96$ \\
\hline Place of Residence (Ref-Urban) & & & 1.19 & $0.82-1.72$ & 1.06 & $0.74-1.52$ \\
\hline Child repeated a grade (Ref-No) & & & $0.24^{* * *}$ & $0.17-0.33$ & $0.25^{* * *}$ & $0.18-0.35$ \\
\hline \multicolumn{7}{|l|}{ Parental Education (Ref- $\leq$ primary) } \\
\hline Some secondary & & & & & $1.53^{* *}$ & $1.00-2.34$ \\
\hline Complete secondary & & & & & $3.47^{* * *}$ & $2.00-5.90$ \\
\hline Missing & & & & & 1.28 & $0.71-2.28$ \\
\hline
\end{tabular}

${ }^{*} p<0.10,{ }^{* *} p<0.05,{ }^{* * *} p<0.005$

When controlling for parental education in Model3, young people from non-disrupted non-resident parent families and disrupted co-resident parent families were up to 51\% and $49 \%$ less likely to complete high school relative to those in undisrupted co-resident parent families, respectively. Gender and repeating a grade also significantly accounted for high school completion while offspring of parents with at least some secondary school $(\mathrm{aOR}=1.53)$ or complete secondary education $(\mathrm{aOR}=3.47)$ were more likely to complete high school relative to those whose parents had primary education or less. We did not find any statistical significance for the missing category.

The second part of our analysis involved distinguishing between the effect of the exiting or entrance of a parent on high school completion. Table 5 presents this subgroup analysis

Table 5. Subgroup analysis of types of type of family structure changes, (NIDS waves 1-5).

\begin{tabular}{lcccccc}
\hline \multirow{2}{*}{ Variables } & \multicolumn{2}{c}{ Model 1 } & \multicolumn{2}{c}{ Model 2 } & Model 3 \\
\cline { 2 - 6 } & OR & CI & aOR & CI & AaR & CI \\
\hline Exit of a parent(s) (ref is undisrupted co-resident) & $0.51^{* * *}$ & $0.27-0.97$ & $0.54^{* *}$ & $0.27-1.10$ & 0.85 & $0.22-3.21$ \\
Exit of a parent (ref is undisrupted lone resident parent) & 1.44 & $0.81-2.56$ & $1.75^{* * *}$ & $0.93-3.29$ & 1.61 & $0.83-3.18$ \\
Entrance of a parent (ref is stable non-resident parent) & 0.89 & $0.49-1.63$ & 0.94 & $0.51-1.73$ & 1.12 & $0.57-2.17$ \\
Entrance of a parent (ref is stable co-resident) & 0.70 & $0.37-1.33$ & 1.12 & $0.57-2.17$ & 0.23 & $0.39-1.36$ \\
\hline
\end{tabular}


The first estimate in each subgroup is from a model which only included two predictors, i.e., the subgroup and household income change, while the second estimate was taken from a model which included the controls used in Model 2 in Table 4. The third estimate included all the controls used in Model 3 (Table 4). In the first model, we find that young people from two-parent families who experienced the exiting of one or both parents were less likely $(\mathrm{OR}=0.51)$ to complete high school relative to those who did not experience any disruption. We did not find any statistically significant effect on the other categories. In Model 2, the exiting of a parent from a co-resident parent family structure was still significantly associated with high school completion $(\mathrm{aOR}=0.54)$. A somewhat surprising finding was that young people who experienced the moving out of a single parent and hence were left with no resident parent were $75 \%$ more likely to complete high school relative to those who resided in undisrupted single-parent families. In Model 3, none of the family structure change subgroups were statistically significant.

\section{Discussion}

In this study, we have examined the effect of family structure changes on high school completion. We specifically considered whether the effect differed by types of disruption, including the exiting or entrance of a parent. The present study is the first (to our knowledge) to examine the effect of family structure changes on educational outcomes in South Africa, although there have been several other studies (for example (Ndagurwa and Nzimande 2016; Branson et al. 2014; Anderson 2003)) that have examined the effect of family structure on educational outcomes.

Education is a crucial element in human capital development, the basis for skills development and is both a catalyst and essential for the achievement of all Sustainable Development Goals (SDGs) (Sterling 2016). High school completion is critical as it is the path towards post-secondary school education and ultimately, the labour market (Bengesai et al. 2018; Clark and Mathur 2012). For instance, there is empirical evidence which suggests that individuals who do not graduate from high school have bleak economic prospects (Stats SA 2014). Moreover, educational attainment has been linked to differences in physical and psychological wellbeing. Thus, poor educational outcomes can potentially lead to lead to other types of disadvantage (Steele et al. 2009). Considering the importance of education in shaping adult outcomes, research must explore how it is distributed and factors that might impact on its distribution.

Although access and participation in education has improved in South Africa since the demise of apartheid, the analysis in this study reveals that almost $50 \%$ of the young people had not completed high school by ages 21-23. This is likely due to the high dropout rates that seem to scourge the South African education system (Weybright et al. 2017). For instance, it is estimated that the mean years of schooling in South Africa is 9.9 years (UNESCO Institute for Statistics 2013), suggesting that a significant proportion of young people do not progress beyond the Grade 10 level (Spaull 2013). We also found that a considerable number of children do not grow up in traditional nuclear families, confirming both official statistics as well as earlier studies on family structure in South Africa (Stats SA 2017; Sooryamoorthy and Makhoba 2016).

Regarding family structure disruption, a key finding from our study is that individuals who do not reside with both their parents are up to 50\% less likely to complete high school. This effect is more pronounced for young people from stable non-resident parent families as well as those in disrupted co-resident parent family structures. How can these results be interpreted? First, consistent with past research, our findings reinforce the notion that perhaps what 'counts' is residing with both parents (Hampden-Thompson and Galindo 2015; McLanahan and Sandefur 1994) who often have greater resources at their disposal than in other family structures. Co-resident parents are likely to have a dual income and can share time to spend with their children relative to single parents. For South Africa, our findings are especially important given that majority of young people do not reside with both parents, with a significant proportion living in non-resident parent family structures (Stats SA 2017; Sooryamoorthy and Makhoba 2016; Chuong and Operario 2012). These disparities are also stratified by 
race and socioeconomic status. To illustrate, Stats SA (2017) reports that only $21 \%$ of African children resided with both parents relative to $67 \%$ and $61 \%$ of the White and Indian children, respectively. Thus, disparities in family structure add another layer of inequality which should be of concern to policymakers in South Africa.

Our findings from the subgroup analysis also confirmed the hypothesis that not all family structure changes have an equal effect (Sun and Li 2011; Lee and McLanahan 2015). For young people who resided with both parents at ages 12, 13 and 14, the exiting of a parent from a two-parent family structure significantly reduced their odds of completing high school by up to $50 \%$ when compared with those who remained in stable co-resident parent families, although this effect became insignificant when parental education was added. On the contrary, and rather surprising was the fact that the moving out of a parent from a lone-parent family structure either due to death or other reasons not provided in the data set, increased the odds of completing high school. One interpretation for this is that a significant number of South African children live in extended families, with relatives such as grandparents, uncles and aunts (Hall and Mokomane 2018). For the Black South African racial group, this is especially the case where the mother is unmarried. Hence, there is a possibility that in the event of the death of the parent, or migration due to work, young people from the lone-parent household might be less affected by the change as the extended family might provide a safety net for them (Foster 2000). In other words, there is the possibility that the presence of additional adults, especially in Black African extended families might fulfil the same support found in co-resident families. However, these explanations have not been empirically tested in South Africa and thus remain speculatory. There is, therefore, need for further research into why the exiting of a parent from a lone parent family structure might be beneficial to young people. It might be equally important to investigate whether the timing of these events (i.e., the exit of the parent) might explain the variation in the effect of not living with both parents between young people who were in non-resident parent families at Wave 1 , and those who experienced this change during the observation period.

The fact that high school completion was not attributable to household income change was rather surprising as research has long established income-based inequality in educational outcomes (Assari 2018; Branson et al. 2014). In the absence of alternative explanations, we attribute the insignificant effect of household income change to the possibility of multicollinearity between with family structure change. It is likely, changes in family structure are directly associated with changes in household income, in which case, the significance of the coefficient might be misleading. Other factors that were found to be insignificantly associated with high school completion are race and place of residence.

The link between gender and educational outcomes is no longer questioned. There is robust research which has shown that females are progressing through education faster than males, although in some cases, the gender differences are small (Lam and Branson 2014; Eloundou-Enyegue et al. 2009). Thus, our study confirms these prior studies which have identified a female advantage in mean years of schooling.

Grade repetition is a common practice in many countries (UNESCO Institute for Statistics 2012). In South Africa, it is often considered a valid corrective action when the learning objectives of a particular grade have not been achieved (Branson et al. 2014). However, the evidence regarding the association between grade repetition and educational attainment is inconclusive, with some studies suggesting that it is beneficial for the student, while others have found the opposite (Branson et al. 2014; Ikeda and Garcia 2014). There is a possibility that repeating a grade may be discouraging to some individuals and affect their attitudes towards school, leading to dropout. However, if pedagogically effective, it may improve the acquisition of knowledge, leading to increased retention, although delaying completion of the schooling cycle. Nonetheless, in terms of this study, even if they persist, individuals who repeat grades are most likely to fall behind in terms of grade level, perhaps explaining why they had not completed high school by the given time. 
Parental education has been shown to be one of the strongest determinants of children's educational outcomes. It is often used as a proxy for socioeconomic status and has been shown to influence children's outcomes (Martin 2012) through financial investments in children's education as well as the transfer of skills and habits to their children through behaviour modelling (Hampden-Thompson and Galindo 2015; Chevalier et al. 2013). Better educated parents are also knowledgeable about the returns from education and therefore might be willing to invest more money in providing quality education for their offspring (Erola et al. 2016). Expectedly, we also found that the offspring of parents who had some secondary level education or completed high school had the best educational outcomes. This suggests that the parent's educational status, and by extension, the socioeconomic status might be more important than family structure instability (Chevalier et al. 2013). However, given the wide confidence interval for both the 'some secondary school' and 'complete secondary school' categories in our analysis, these results should be interpreted with caution. As mentioned earlier, the probability of missing parental education was largely associated with family structure, in particular, among young people who lived with both their parents. It is also possible that the composite parental education variable used in this study might have masked the real effect of parental education.

In conclusion, our findings suggest that children who grow up in alternative family structures and more so, those who experience a change from two-parent family structures have poorer educational outcomes. Family instability caused by the exiting of a parent has important consequences for high school completion even after controlling for other factors. Thus, the finding lends support to the notion that other family structures might be 'incomplete institutions' which do not provide children with the necessary resources needed for success (Nock 1995). We, therefore, propose that research on family structure in South Africa should consider the family structure changes that young people are exposed to during their life course as one of the key determinants of educational attainment. Such a refined understanding of the family as an institution in transition will also assist policymakers in coming up with holistic interventions to support families as well as allocate public resources in ways that can help reduce educational inequalities.

Although this study has some notable strengths, we acknowledge that there are some limitations. First, the study only focused on parent-child relationships. We recognise that the diversity of the family goes beyond this. This might include co-residence with grandparents, step-parents and step-siblings and it is recommended that future studies might also consider these family structure complexities. Second, physical residence with parents was captured in this study when the individuals were aged 12-14 years old (NIDS wave 1) and, hence might not adequately capture the dynamics of the family structure during an individual's childhood. These limitations notwithstanding, the present study has managed to highlight the prevalence of family structure disruption in South Africa and the association with a particular educational outcome. Given that family structure disruption is a widespread phenomenon, the findings from this study are not only relevant to South Africa but will resonate in many other contexts where children are growing up in non-traditional and fragile families.

Author Contributions: Both A.V.B. and N.N. conceptualised and designed the research together. A.V.B. took the lead in data analysis and writing up the paper while N.N. provided critical feedback as well as editing. Both authors have read the final version of this manuscript and agreed to the published version of the manuscript.

Funding: This research received no external funding.

Acknowledgments: We would like to thank the Southern African Labour and Development Research Unit (SALDRU) for allowing us to use the data from the National Income Dynamics Study.

Conflicts of Interest: The authors declare no conflict of interest.

\section{References}

Abuya, Benta A., Maurice Mutisya, Elijah O. Onsomu, Moses Ngware, and Moses Oketch. 2019. Family Structure and Child Educational Attainment in the Slums of Nairobi, Kenya. Sage Open 9: 1-10. [CrossRef]

Amoateng, Acheampong Y., Tim B. Heaton, and Camille McAlmont. 2017. Family Structure and Children's Schooling in sub-Saharan Africa. African Sociological Review 21: 77-97. 
Anderson, Kermyt G. 2003. Family Structure, Schooling Outcomes, and Investment in Education in South Africa. University of Michigan: Population Studies Centre. Available online: https://www.psc.isr.umich.edu/pubs/ pdf/rr03-538.pdf (accessed on 18 November 2019).

Assari, Shervin. 2018. Diminished Economic Return of Socioeconomic Status for Black Families. Social Sciences 7: 74. [CrossRef]

Astone, Nan M., and Sara S. McLanahan. 1991. Family Structure, Parental Practices and High School Completion. American Sociological Review 56: 309-20. [CrossRef]

Baigrie, Nic, and Katherine Eyal. 2013. An Evaluation of the Determinants and Implications of Panel Attrition in the National Income Dynamics Survey (2008-2010). South African Journal of Economics 82: 39-65. [CrossRef]

Bengesai, Annah V., Hafiz T. A. Khan, and Russell Dube. 2018. Effect of Early Sexual Debut on High School Completion. Journal of Biosocial Science 50: 124-43. [CrossRef]

Bourdieu, Pierre. 1986. The Forms of Capital. In Handbook of Theory and Research for Sociology of Education. Edited by John G. Richardson. New York: Greenwood Press.

Branson, Nicola, Clare Hofmeyr, and David Lam. 2014. Progress through School and the Determinants of School Dropout in South Africa. Development Southern Africa 31: 106-26. [CrossRef]

Budlender, Debbie, and Francie Lund. 2011. South Africa: A Legacy of Family Disruption. Development and Change 42: 925-46. [CrossRef]

Chevalier, Arnaud, Harmon Colm, Vincent O'Sullivan, and Ian Walker. 2013. The impact of parental Income and Education on the Schooling of their Children. IZA Journal of Labor Economics 2: 1-22. [CrossRef]

Chinhema, Michelle, Timothy Brophy, Michael Brown, Murray Leibbrandt, Cecil Mlatsheni, and Ingrid Woolard. 2016. National Income Dynamics Study Panel User Manual, Technical Report. Cape Town: Southern Africa Labour and Development Research Unit, Available online: http://www.nids.uct.ac.za/images/documents/ wave4/20170227-NIDS-W4PanelUserManual-V1.1.pdf (accessed on 29 June 2020).

Chuong, Caroline, and Don Operario. 2012. Challenging Household Dynamics: Impact of Orphanhood, Parental Absence, and Children's Living Arrangements on Education in South Africa. Global Public Health 7: 42-57. [CrossRef]

Cid, Alejandro, and Charles E. Stokes. 2013. Family Structure and Children's Education Outcome: Evidence from Uruguay. Journal of Family and Economic Issues 34: 185-99. [CrossRef]

Clark, Shelley, and Rohini Mathur. 2012. Dating, Sex, and Schooling in Urban Kenya. Studies in Family Planning 43: 161-74. [CrossRef] [PubMed]

Coleman, James S. 1988. Social Capital in the Creation of Human Capital in Organisations and Institutions: Sociological and Economic Approaches to the Analysis of Social Structure, supplement. The American Journal of Sociology 94: S95-120. [CrossRef]

Eloundou-Enyegue, Parfait M., Fouadi Makki, and Sarah Giroux. 2009. Sex versus SES: A Declining Significance of Gender for Schooling in sub-Saharan Africa. In Gender, Equality and Education from International and Comparative Perspectives. Edited by David P. Baker and Alexander W. Wiseman. Bingley: Emerald Group Publishing Limited, pp. 1-37.

Erola, Jani, Sanni Jalonen, and Hannu Lehti. 2016. Parental Education, Class and Income over Early Life Course and Children's Achievement. Research on Social Stratification and Mobility 44: 33-43. [CrossRef]

Fomby, Paula, and Andrew J. Cherlin. 2007. Family Instability and Child wellbeing. American Sociological Review 72: 181-204. [CrossRef] [PubMed]

Foster, G. 2000. The capacity of the extended family safety net for orphans in Africa. Psychology, Health and Medicine 5: 55-62. [CrossRef]

Frisco, Michelle L., Chandra Muller, and Kenneth Frank. 2007. Parents' Union Dissolution and Adolescents' School Performance: Comparing Methodological Approaches. Journal of Marriage and Family 69: 721-41. [CrossRef]

Furstenberg, Frank F., and Judith A. Seltzer. 1986. Divorce and Child Development. Sociological Studies of Child Development 1: 137-60.

Goldberg, Rachel E. 2013. Family instability and early initiation of sexual activity in Western Kenya. Demography 50: 725-50. [CrossRef]

Hall, Katharine, and Zitha Mokomane. 2018. The Shape of Children's Families and Households. A Demographic Review. In South African Child Gauge. Edited by Katharine Hall, Linda Richter, Zitha Mokomane and Lori Lake. Cape Town: Children's Institute, University of Cape Town, pp. 32-35. 
Hall, Katharine, and Winnie Sambu. 2018. Demography of South Africa's Children. In South African Child Gauge. Edited by Aislinn Delany, Selwyn Jehoma and Lori Lake. Cape Town: Children's Institute, University of Cape Town, pp. 132-36.

Hampden-Thompson, Gillian, and Claudia Galindo. 2015. Family Structure Instability and the Educational Persistence of Young People in England. British Education Research Journal 41: 749-66. [CrossRef]

Humble, Steve, and Pauline Dixon. 2017. The Effects of Schooling, Family and Poverty on Children's Attainment, Potential and Confidence-Evidence from Kinondoni, Dar es Salaam, Tanzania. International Journal of Educational Research 83: 94-106. [CrossRef]

Ikeda, Miyako, and Emma Garcia. 2014. Grade Repetition: A Comparative Study of Academic and Non-Academic Consequences. OECD Journal of Economic Studies 1: 269-315. [CrossRef]

Lam, David, and Nicola Branson. 2014. Education in South Africa since 1994. In The Oxford Companion to the Economics of South Africa. Edited by Harun Borat, Alan Hirsh, Ravi Kanbur and Mthuli Ncube. Oxford: Oxford University Press.

Lee, Dohoon, and Sara McLanahan. 2015. Family Structure Transitions and Child Development: Instability, Selection, and Population Heterogeneity. American Sociological Review 80: 738-63. [CrossRef] [PubMed]

Li, Ying, Tongtong Hu, Tingshuai Ge, and Emma Auden. 2019. The Relationship between Home-based Parental Involvement, Parental Educational Expectation and Academic Performance of Middle School Students in Mainland China: A Mediation Analysis of Cognitive Ability. International Journal of Educational Research 97: 139-53. [CrossRef]

Madhavan, Sangeetha, and Enid J. Schatz. 2007. Coping with Change: Household Structure and Composition in Rural South Africa, 1992-20031. Scandinavian Journal of Public Health 35: 85-93. [CrossRef]

Marteleto, Leticia, David Lam, and Vimal Ranchhod. 2008. Sexual Behaviour, Pregnancy, and Schooling among Young People in Urban South Africa. Studies in Family Planning 39: 351-68. [CrossRef]

Martin, Molly A. 2012. Family Structure and the Intergenerational Transmission of Educational Advantage. Social Science Research 4: 33-47. [CrossRef]

McLanahan, Sara, and Gary Sandefur. 1994. Growing up with a Single Parent. Cambridge: Harvard Univ. Press.

Monash, Roeland, and Ties J. Boerma. 2004. Orphanhood and Childcare in sub-Saharan Africa: An Analysis of National Surveys from 40 Countries. AIDS 18: S55-66. [CrossRef]

Monserud, Maria A., and Glen H. Elder. 2011. Household Structure and Children's Educational Attainment: A Perspective on Co-residence with Grandparents. Journal of Marriage and the Family 73: 981-1000. [CrossRef]

Murray, Leibbrandt, Ingrid Woolard, and Louise De Villiers. 2010. The South African National Income Dynamics Study: Design and methodological issues. Journal for Studies in Economics and Econometrics 34: 7-24.

Ndagurwa, Pedzisayi, and Nompumelelo Nzimande. 2016. The Impact of Family Structure on Schooling Outcomes for Children in South Africa. In Children in South African Families. Edited by Monde Makiwane, Mzikazi Nduna and Nene Earnest Khalema. Newcastle: Cambridge Scholars Publishing, pp. 58-115.

Nock, Steven L. 1995. A Comparison of Marriages and Cohabiting Relationships. Journal of Family Issues 16: 53-76. [CrossRef]

Posel, Dorrit, and Stephanie Rudwick. 2013. Changing patterns of marriage and cohabitation in South Africa. Acta Jurdica 13: 169-80.

Schatz, Enid, Sangeetha Madhavan, and Jill Williams. 2011. Female-headed Households Contending with Aids-Related Hardship in Rural South Africa. Health and Place 17: 598-605. [CrossRef] [PubMed]

Sooryamoorthy, Randamany, and Mzwandile Makhoba. 2016. The Family in Modern South Africa: Insights from Recent Research. Journal of Comparative Family Studies 47: 309-21. [CrossRef]

Spaull, Nic. 2013. South Africa's Education Crisis: The quality of education in South Africa 1994-2011. Report Commissioned by Center for Development and Enterprise. Johannesburg: Centre for Development and Enterprise, Available online: https://www.section27.org.za/wp-content/uploads/2013/10/Spaull-2013-CDEreport-South-Africas-Education-Crisis.pdf (accessed on 17 December 2019).

Spaull, Nic. 2015. Schooling in South Africa: How Low-quality Education becomes a Poverty trap. 2015. In South African Child Gauge. Edited by Ariane De Lannoy, Sharlene Swartz, Lori Lake and Charmaine Smith. Cape Town: Children's Institute, University of Cape Town, pp. 34-40.

Statistics South Africa. 2014. Poverty Trends in South Africa: An Examination of Absolute Poverty between 2006 and 2011; Pretoria: Statistics South Africa. Available online: https://www.statssa.gov.za/publications/Report-0310-06/Report-03-10-062015.pdf (accessed on 14 January 2020). 
Statistics South Africa. 2017. Mid-Year Population Estimates 2017; Pretoria: Statistics South Africa. Available online: https://www.statssa.gov.za/publications/P0302/P03022017.pdf (accessed on 14 January 2020).

Steele, Fiona, Wendy Sigle-Rushton, and Øystein Kravdal. 2009. Consequences of Family Disruption on Children's Educational Outcomes in Norway. Demography 46: 553-74. [CrossRef]

Sterling, Stephen. 2016. A Commentary on Education and Sustainable Development Goals. Journal of Education for Sustainable Development 10: 208-13. [CrossRef]

Sun, Yongmin, and Yuanzhang Li. 2011. Effects of Family Structure Type and Stability on Children's Academic Performance Trajectories. Journal of Marriage and the Family 73: 541-56. [CrossRef]

Tsiplakides, Iakovos. 2018. Differentiation in Higher Education: The Impact of Parental Education. Social Sciences 7: 28. [CrossRef]

UNESCO Institute for Statistics. 2012. Opportunities Lost: The Impact of Grade Repetition and Early School Leaving. Montreal: UNESCO, Available online: https://unesdoc.unesco.org/ark:/48223/pf0000218449 (accessed on 17 December 2019).

UNESCO Institute for Statistics. 2013. UIS Methodology for of Mean Years of Schooling. Montreal: UNESCO, Available online: http://uis.unesco.org/sites/default/files/documents/uis-methodology-for-estimation-ofmean-years-of-schooling-2013-en_0.pdf (accessed on 17 December 2019).

Uwaifo, V. O. 2012. The Effects of Family Structures on the Academic Performance of Nigerian University Students. Global Journal of Human Social Science 12: 53-56. [CrossRef]

Weybright, Elizabeth H., Linda L. Caldwell, Hui Xie, Lisa Wegner, and Edward A. Smith. 2017. Predicting Secondary School Dropout among South African Adolescents: A Survival Analysis Approach. South African Journal of Education 37: 1-11. [CrossRef]

Wittenberg, Martin. 2009. Weights: Report on NIDS Wave 1. Technical Paper No. 2. Cape Town: SALDRU, UCT.

(C) 2020 by the authors. Licensee MDPI, Basel, Switzerland. This article is an open access article distributed under the terms and conditions of the Creative Commons Attribution (CC BY) license (http://creativecommons.org/licenses/by/4.0/). 